\title{
Quality of life measurement for patients undergoing treatment for lung cancer
}

\author{
R J Fergusson, A Cull
}

The outlook for most patients with lung cancer remains bleak, with an overall five year survival rate of less than $10 \%$. Surgery still offers the best chance of cure in the small group of patients with resectable lesions. The life span of patients with small cell tumours has been extended by combination chemotherapy but long term survival is rare. Nearly all patients are therefore treated with palliative intent.

The outcome of treatment has traditionally been measured in terms of the extent and duration of tumour response and the patient's survival time. In the absence of major therapeutic advances in the past decade, differences between treatments as measured by these biological indices have been small and it has become increasingly relevant to compare the cost (in terms of morbidity) at which any gain is achieved. The psychosocial issues raised by the disease and its treatment have recently been comprehensively reviewed. ${ }^{12}$

Scales for monitoring toxicity related to treatment $^{3}$ and performance status ${ }^{3-5}$ are widely used but inadequate for assessing some key aspects of patients' experience-for example, pain and nausea-that are essentially subjective. Furthermore, .clinical experience shows that patients with apparently similar performance status and toxicity may experience substantially different quality of life. Although good clinicians consider quality of life as an important variable, most also regard it as a matter of clinical judgement: the "art" as opposed to the "science" of medicine. These assessments are unsystematic and subjectively biased and more reproducible methods are required for use in (1) auditing clinical practice, (2) evaluating treatment outcome in clinical trials, (3) informed decision making in the care of individual patients, (4) justifying needs for supportive services, and (5) allocating resources for medical services.

Vigorous research efforts by clinicians and social scientists over the past decade have resulted in a bewildering array of quality of life measures, but only by sustained collaboration can the reliability and validity of these instruments be ascertained and common problems in data collection and analysis overcome. Those unfamiliar with developments in this subject may view the task of accumulating "soft" data as cumbersome and time consuming, but considerable progress has been made and many of these qualms can now be dispelled. Systematic inquiry has sometimes revealed quality of life outcomes that were counterintuitive. ${ }^{6}$

\section{What is "quality of life"?}

The concept of quality of life may be accepted as a basis for clinical decision making but it is often used with so comprehensive a meaning that it defies precise definition. There is now general agreement ${ }^{7}$ that quality of life in the context of health is a multidimensional concept concerned with the impact of physical symptoms and side effects of treatment on patients' functioning and psychosocial wellbeing. Specific research questions may justify a narrower focus but studies sampling only one of these domains cannot adequately reflect the patient's quality of life. A second point of consensus is that the emphasis should be placed on assessing the subjective experience of the person whose quality of life is in question. ${ }^{8}$

\section{Can quality of life be measured?}

It follows from this definition that indirect indicators such as time in hospital or days off work may provide valuable information about the outcome of treatment but are inadequate as measures of quality of life. What is required is an instrument that measures relevant symptoms and side effects and their impact on the patient's physical functioning, emotional state, and social activity. The ideal method should be short, easy to administer, and easy to interpret and should have validity, adequate reliability, and responsiveness to change over time. The choice of a specific test always depends on the particular question being asked and any one "gold standard" test is unlikely to be applicable to all circumstances. Some generic health measures ${ }^{910}$ have been validated for use with patients suffering from cancer, but several new tools have now been developed specifically for assessing quality of life in these patients. Several excellent reviews of available instruments have been published recently. ${ }^{11-13}$ Selection of a particular method raises several questions for consideration.

Performance indices and doctors' ratings Patients' performance status and the response
Reprint requests to: Dr RJ Fergusson Respiratory Medicine Unit, City Hospital, Edinburgh EH10 5SB 
Table 1 Doctors' rating scales for quality of life

\begin{tabular}{|c|c|c|c|c|c|}
\hline \multirow[b]{2}{*}{$\begin{array}{l}\text { Name and } \\
\text { reference }\end{array}$} & \multicolumn{3}{|l|}{ Domains } & \multirow[b]{2}{*}{$\begin{array}{l}\text { No of } \\
\text { items }\end{array}$} & \multirow[b]{2}{*}{ Scoring } \\
\hline & Physical & Functional & $\begin{array}{l}\text { Psycho- } \\
\text { logical Social }\end{array}$ & & \\
\hline Karnofsky ${ }^{4}$ & + & + & & 1 & $0-100$ \\
\hline $\mathrm{WHO}^{3}$ & + & + & & 1 & $0-4$ \\
\hline $\mathrm{ECOG}^{5}$ & + & + & & 1 & $0-4$ \\
\hline Carlens $^{18}$ & + & + & & 1 & $+20--2$ \\
\hline Spitzer $^{19}$ & + & + & + & 5 & $0-10$ \\
\hline
\end{tabular}

ECOG-Eastern Cooperative Oncology Group.

to treatment and its toxic effects are generally assessed by the physician. Examples of observer scales are listed in table 1. The Karnofsky performance index ${ }^{4}$ has been in use longest and is still widely favoured as a prognostic indicator, though inter-rater reliability is unsatisfactory ${ }^{14}$ and is related to the experience of the assessor. ${ }^{15}$ Scores are also influenced by whether the evaluation is performed at home or in hospital. ${ }^{16}$ The World Health Organisation ${ }^{3}$ and Eastern Cooperative Oncology Group (ECOG) ${ }^{5}$ scales share many of the same limitations. Although reliability can be improved by training raters, ${ }^{17}$ these instruments all neglect psychosocial variables and to that extent remain unsatisfactory as measures of quality of life.

The Carlens Vitagram ${ }^{18}$ was specifically developed for use with patients with lung cancer. It is based on a points system that reflects working capacity and time in hospital as well as physical symptoms and functional capacity. It is therefore a performance index. The Spitzer scale ${ }^{19}$ is a quick and easy measure that addresses a more comprehensive range of quality of life issues, but it has too few items in each domain for sensitive scaling.

Comparison of doctors and patients' ratings of the patient's quality of life based on several of these instruments showed poor agreement, suggesting that physicians could not accurately determine what patients felt. ${ }^{20}$ Furthermore, inter-rater reliability between health professionals was poor. Where possible, patients' "self report" measures should be included in the assessment of quality of life.

Is quality of life assessment by patients really feasible?

Clinical experience and published data suggest that the overwhelming majority of patients with cancer welcome the opportunity to report their experience even within the confines of a formal research study, ${ }^{21}$ but care should be taken that all the questions are easy to read and interpret. Visual analogue scales have commonly been used ${ }^{22-24}$ but they may be difficult for patients to understand $\mathrm{d}^{25}$ and are time consuming to score. A questionnaire should specify the time period to which the questions refer (for example, the past 24 hours, the past three days, etc) and it is important to consider carefully how often measures need to be repeated. There may be considerable loss of compliance if the cumulative burden on the patient is too great, particularly when performance is deteriorating. ${ }^{25} \mathrm{~W}$ ith this in mind the Medical Research Committee has favoured the diary card developed for use in lung cancer ${ }^{26}$ as a means of obtaining frequently repeated measures of a limited number of variables over time.

The most prevalent problem reported in conducting quality of life studies has been in obtaining the cooperation of medical staff. ${ }^{78}$ Where it can be shown that questions relevant to the clinician can be addressed by procedures that can be accommodated in clinical practice scepticism can be overcome, but some commitment is required by a member of staff to ensure the quality control of the data collected.

\section{Which self report measure should be} used?

Although the standardised interview conducted by a trained interviewer may yield the best data, this is expensive, time consuming, and impractical for most clinical studies, where large numbers of patients may be participating. Attention has largely focused on data collected by questionnaire and diary card.

Measures designed for use across a wide range of chronic diseases ${ }^{927}$ are often lengthy and hence unsuitable for studies requiring repeated testing, particularly among debilitated patients. The Psychological Adjustment to Illness Scale ${ }^{10}$ was originally published as a semi-structured interview with normative data for lung cancer patients covering seven quality of life domains. It is now available as a self report questionnaire with good reliability and validity but it has the disadvantage that it is copyright and expensive to obtain and, in common with other generic measures, it fails to assess specific physical symptoms or side effects.

There has been a great temptation for researchers to develop ad hoc, study specific measures with the problem that reliability and validity testing are neglected and cross study comparisons become impossible. The recommendation at this stage would be to use the best available measure rather than to seek to develop a new one. Some of the most widely used questionnaires that have been applied to quality of life assessment in patients with lung cancer are shown with brief details in table 2 . The Linear Self Assessment System (LASA) ${ }^{28}$ appears to detect change over time but is subject to all the criticisms levelled at visual analogue scales-that is, it is time consuming to score, scores suggest a spurious degree of accuracy, and in group data patients showing equal changes in scores may not show the same evidence of improvement or deterioration. The Functional Living Index-Cancer (FLIC) ${ }^{22}$ is widely used but there have been problems with its format, which imposes seven equal intervals on the analogue scale. It is sometimes now presented as a seven point scale. It has relatively few items referring to symptoms and has been found somewhat insensitive to change over time. The Cancer Rehabilitation Evaluation System (CARES) ${ }^{29}$ is a well developed and comprehensive instrument with a short version that is more practical for research purposes. It focuses on problems amenable to rehabilitative effort and patients can identify areas where they 
Table 2 Multidimensional quality of life measures used with patients with lung cancer

\begin{tabular}{|c|c|c|}
\hline Name and reference & No of items and format & Content \\
\hline Linear Self Assessment System (LASA) ${ }^{28}$ & 25 linear analogue & $\begin{array}{l}\text { Symptoms, physical activity, mood, } \\
\text { social interaction }\end{array}$ \\
\hline Functional Living Index-Cancer (FLIC) ${ }^{22}$ & $\begin{array}{l}22 \text { linear analogue } \\
7 \text { intervals }\end{array}$ & $\begin{array}{l}\text { Symptoms, physical activity, mood, } \\
\text { social interaction }\end{array}$ \\
\hline $\begin{array}{l}\text { Career Rehabilitation Evaluation System } \\
(\text { CARES })^{29}\end{array}$ & $\begin{array}{l}139 \text { or } 594 \text { point scale }+ \\
\text { yes/no }\end{array}$ & $\begin{array}{l}\text { Physical, psychosocial, marital, sexual, } \\
\text { medical, social interaction }\end{array}$ \\
\hline Rotterdam Symptom Checklist (RSCL) $)^{30}$ & 384 point scale & $\begin{array}{l}\text { Physical symptoms, psychological } \\
\text { distress, } 8 \text { item physical function scale }\end{array}$ \\
\hline $\begin{array}{l}\text { EORTC core questionnaire and lung cancer } \\
\text { module }{ }^{3132}\end{array}$ & $\begin{array}{l}30+134 \text { point scale }+ \\
\text { yes/no }\end{array}$ & $\begin{array}{l}\text { Functional state, symptoms, } \\
\text { psychological distress, social } \\
\text { interaction, financial state, global health } \\
\text { and quality of life }\end{array}$ \\
\hline
\end{tabular}

EORTC-European Organisation for Research on the Treatment of Cancer

would like to have help. The main obstacle to its use in Britain is its cost. The Rotterdam Symptom Checklist (RSCL) ${ }^{30}$ is a particularly clear questionnaire, which is increasingly popular because it is widely applicable and easy for patients to complete. It was recommended by the Medical Research Council's working party on the quality of life. ${ }^{11}$ Its particular advantage is its flexibility, which allows extra items to be incorporated if additional illness or treatment related variables need to be assessed.

Attention is, however, drawn to the measure developed by the quality of life study group of the European Organisation for Research on the Treatment of Cancer (EORTC). International cooperation over several years has resulted in a core questionnaire covering the generic impact of cancer and its treatment ${ }^{31}$ and a 13 item module $^{32}$ of items specifically relevant to patients with lung cancer-for example, cough, dyspnoea, pain, and treatment related side effects. This scale has been very carefully developed and promises to be a useful instrument for measuring quality of life in these patients. Full details of the psychometric properties of the final version of the scale are soon to be published.

\section{Quality of life measurement in lung cancer}

Before we consider the effect of treatment on quality of life it is important to remember that left untreated lung cancer has a substantial and progressive impact on patients' quality of life. Poorer performance and more extensive disease are associated with increased psychological distress, ${ }^{33}$ and depressive illness has been reported more commonly among patients who did not have active treatment. ${ }^{34}$

There are surprisingly few reports of quality of life measurements in patients undergoing treatment for lung cancer. The increasing use of chemotherapy for small cell tumours and more recently for non-small cell lung cancer has stimulated most interest in this subject.

\section{CHEMOTHERAPY}

Many early studies of chemotherapy in small cell lung cancer included assessment of functional performance as an attempt to measure the quality of life. ${ }^{35-37}$ Most reported an association between improved scores and response to treatment, though one study ${ }^{35}$ suggested that subsequent maintenance treatment was accompanied by a fall in performance scores. Coates et $a^{37}$ also attempted to assess quality of life by means of a linear analogue self assessment scale, measuring general wellbeing and other specific factors (mood, pain, nausea, vomiting, appetite, breathlessness, and physical activity) and showed a good correlation with performance ratings on the ECOG scale.

The intensity of performance scores for detecting changes in quality of life in lung cancer was highlighted in a recent study ${ }^{38}$ that compared three different instruments (diary cards, the EORTC questionnaire, and the quality of life index of Spitzer et al ) in a small group of patients enrolled in a randomised trial of duration of chemotherapy in small cell lung cancer. The diary cards showed a worsening of quality of survival as treatment continued, which was not seen with the Karnofsky scores. The comparisons between the three quality of life instruments showed the appropriate convergent and divergent validity and showed that the diary cards were more sensitive to short term changes.

Non-small cell lung cancer is a less chemosensitive disease, but for the small proportion of patients who might benefit from this form of treatment would seem a rational choice as most patients have metastatic disease at presentation. In a recent review of the role of chemotherapy in advanced non-small cell lung cancer $^{39}$ Splinter commented that few of the 142 published studies attempted to measure quality of life. In most, the response to treatment correlated with improvement in physical performance, but in others no change was seen and in some ${ }^{4041}$ quality of life as measured by Karnofsky index fell during treatment. The study reported by Bakker et $a l^{41}$ deserves comment. It assessed the effects of three drugs (vindesine, cisplatin, and bleomycin) in an uncontrolled group of relatively fit patients. The authors reported a high response rate $(48 \%)$, with a median survival of 47 weeks in those responding, but concluded that the fall in performance during treatment offset the benefits of treatment.

Most studies of chemotherapy in non-small 
cell lung cancer show only a small survival advantage in responding patients and very few have compared active treatment with the best supportive care. ${ }^{39}$ As only palliation can be expected there would appear to be a strong case for including measurements of quality of life in any future studies.

\section{RADIOTHERAPY}

Although radiotherapy is recognised as being capable of effectively palliating symptoms in patients with lung cancer, little is known of its impact on other aspects of a patient's life. In two studies of combined chemotherapy and radiotherapy in small cell lung cancer ${ }^{3738}$ the periods of radiotherapy were associated with a deterioration in the quality of life. Minet $e t a l^{42}$ randomised 81 patients with inoperable nonsmall cell lung cancer to receive either radiotherapy plus chemotherapy or radiotherapy alone and used the Karnofsky index to assess the quality of survival. No difference in score between the groups was seen and there was no actual survival advantage for either treatment.

Similar results were reported by Kaasa $e t$ a $l^{43}$ and Kaasa and Mastekaasa ${ }^{44}$ in a study of 95 patients with non-small cell lung cancer randomised to receive chemotherapy (cisplatin and etoposide) or radiography $(2 \cdot 8 \mathrm{~Gy} \times 15)$. Quality of life was assessed with a locally developed questionnaire covering psychosocial wellbeing, disease and treatment related symptoms, physical function, and everyday activity. The tumour response rate in the radiotherapy group $(42 \%)$ was double that in the chemotherapy arm but overall survival in the two groups was identical. After two weeks of treatment there was a significant drop in performance for the patients having chemotherapy, presumably reflecting the toxicity of treatment. Subsequently there were no differences in quality of life between the two groups. Of interest was the fact that psychosocial wellbeing correlated closely with disease related symptoms (anorexia, tiredness, pain) but poorly with treatment related effects (nausea, vomiting, alopecia, dysphagia). Thus patients recognised the signs of improvement and worsening of their disease and this was reflected in their wellbeing; but they may have accepted side effects of treatment as the price to pay for a chance of overcoming their cancer, and consequently this had less impact on their overall quality of life. Coates et al reported similar results in patients with small cell lung cancer. ${ }^{37}$

This important finding perhaps should be considered when we decide to withhold treatments with low activity from patients in the belief that we are protecting them from harm when there is little chance of benefit. It emphasises three important points: firstly, that quality of life measures may have a role in decisions about treatment options: secondly, that insensitive instruments, such as performance status, that only cover certain aspects of wellbeing may miss differences in the overall effectiveness of treatments; and, thirdly, that assessment of quality of life must include input from the patient.

\section{SURGERY}

Resection still offers the best chance of cure in patients with lung cancer, but what is their quality of survival and can the surgeon provide any palliation for patient found to be unresectable at thoracotomy? These were the questions addressed by the one major report on quality of life in patients having surgery. ${ }^{45}$ The authors used the Carlens Vitagram to assess the quality of survival. This method has been validated in lung cancer. ${ }^{46}$ The quality of survival in patients cured by resection was excellent. The patients who had an operation but subsequently died of the disease did not have a better quality of survival than non-surgically treated patients with the same stage of disease. The authors concluded that an operation had no palliative effect and the possible benefits of "reducing the tumour burden" could be dismissed. This important finding requires further verification by the more sophisticated methods now available for assessing quality of life.

\section{Conclusions}

Most patients with lung cancer are treated with palliative intent, where, by definition, the focus is on the quality rather than merely the duration of survival, yet relatively few studies report data on quality of life.

Substantial progress has been made in defining the concept of health related quality of life to allow agreement about what is to be assessed. An impressive range of practically useful measures has now been developed for collecting data about patients' subjective experience of disease and treatment in a reliable and valid way. Of particular interest is the modular assessment strategy, whereby a generic measure for patients with cancer can be supplemented by a standardised scale specifically relevant to lung cancer.

Work is continuing to show how quality control in collection of data on quality of life can best be achieved and to address problems that can arise in data analysis in longitudinal studies where there are problems of attrition. Sufficient progress has been made to suggest that assessment of quality of life should be included in the audit of clinical practice and evaluating treatment outcomes in clinical trials. The data obtained could provide an objective basis for informing decision making for individual patients and for making the case for allocation of appropriate resources to medical and supportive services. ${ }^{47} 48$

1. Bernhard J, Ganz PA. Psychosocial issues in lung cance patients (part 1). Chest 1991;99:216-23.

2 Bernhard J, Ganz PA. Psychosocial issues in lung cancer patients (part 2). Chest 1991;99:480-5.

3 World Health Organisation. Handbook for reporting results of cancer treatment. Geneva: WHO, 1979.

4 Karnofsky DA, Abelmann WH, Craver LF, Burchenal JH. The use of nitrogen mustards in the palliative treatment of carcinoma. Cancer 1948;1:634-56.

5 Zubrod CG, Schneiderman M, Frei E, et al. Appraisal of methods for the study of chemotherapy of cancer in man. $J$ Chron Dis 1960;11:7-33.

6 Sugarbaker PH, Barofsky I, Rosenberg SA, Gianola FJ. Quality of life assessment of patients in extremity sarcom clinical trials. Surgery 1982;91:17-23.

7 Aaronson NK. Methodologic issues in assessing the quality 
of life of cancer patients. Cancer 1991;67 (suppl):844-50. 8 Aaronson NK, Meyerowitz BE, Bard M, et al. Quality of life research in oncology. Cancer 1991;67(suppl):839-43.

9 Bergner M, Bobbit RA, Carter WB, Gibson BS. The Sickness Impact Profile:development and final revision of a health status measure. Med Care 1981;19:787-805.

10 Morrow GR, Chiarello RJ, Derogatis LR. A new scale for assessing patients psychological adjustment to medical illness (PAIS). Psychol Med 1978;8:605-10.

11 Maguire P, Selby P. Assessing quality of life in cancer patients. Br J Cancer 1989;60:437-40.

12 Moinpour $\mathrm{CH}$, Feigl $\mathrm{P}$, Metch $\mathrm{B}$, Hayden KA, Meysken FL, Crowley J. Quality of life end points in cancer clinical trials: reviews and recommendations. J Natl Cancer Inst 1989;81:485-95.

13 Fallowfield $L$. The quality of life: the missing measuremen in health care. London: Souvenir Press, 1990.

14 Hutchinson TA, Boyd NF, Feinstein AR, et al. Scientific problems in clinical scales, as demonstrated in the Karnofsky index of performance status. J Chron Dis 1979; 32:661-6.

15 Mor V, Laliberte L, Morris JN, Wiemann M. The Karnofsky Performance Status scale. An examination of its reliability and validity in a research setting. Cancer 1984;53:2002-7.

16 Yates JW, Chalmer B, McKegney FP. Evaluation of patients with advanced cancer using the Karnofsky Performance Status. Cancer 1980;45:2220-4.

17 Schag CC, Heinrich RL, Ganz PA. Karnofsky performance status revisited: reliability, validity and guidelines. $\mathrm{J} \mathrm{Clin}$ Oncol 1984;2:187-93.

18 Carlens E, Dahlstrom G, Nou E. Comparative measurements of quality of survival of lung cancer patients after diagnosis. Scand J Respir Dis 1970;51:268-75.

19 Spitzer WO, Dobson AJ, Hall J, et al. Measuring the quality of life of cancer patients. J Chron Dis 1981;34:585-98.

20 Slevin ML, Plant H, Lynch D, Drinkwater J, Gregory WM Who should measure quality of life, the doctor or the patient? Br J Cancer 1988;57:109-12.

21 Fallowfield LJ, Baum M, Maguire GP. Do psychological studies upset patients? JR Soc Med 1987;80:59.

22 Schipper H, Clinch J, McMurray A, Levitt M. Measuring the quality of life of cancer patients. Functional living index-cancer: development and validation. J Clin Oncol 1984;2:472-83.

23 Fernandez C, Rosell R, Abad-Esteve A, et al. Quality of life during chemotherapy in non-small cell lung patients. Acta Oncol 1989;28:29-33.

24 Selby PJ, Chapman JAW, Etazadi-Amoli J, Dalley D, Boyd NF. The development of a method for assessing quality of life of cancer patients. Br J Cancer 1984;50:13-22.

25 Ganz PA, Haskell CM, Figlin RA, La Soto N, Sian J. Estimating the quality of life in a clinical trial of patients with metastatic lung cancer using the Karnofsky Performance Status and the Functional Living Index-Cancer. Cancer 1988;61:849-56.

26 Bleenhen NM, Fayers PM, Girling DJ, Stephens RJ. Survival adverse reactions and quality of life during combination chemotherapy compared with selective palliative treatment for small cell lung cancer. Respir Med 1989;83:51-8.

27 Hunt SM, McEwen J. The development of a subjective health indicator. Sociology of Health and Illness. 1980; 2:231-46.

28 Priestman TJ, Baum M. Evaluation of quality of life in patients receiving treatment for advanced breast cancer. Lancet 1976;i:899-901.

29 Schag CC, Heinrich RL. Cancer rehabilitation evaluation system. Los Angeles: Cares Consultants, 1988

30 de Haes KJM, van Knippenberg FCE, Neijt JP. Measuring psychological and physical distress in cancer patients: structure and application of the Rotterdam Symptom Checklist. Br J Cancer 1990;62:1034-8.

31 Aaronson NK, Bullinger M, Ahmedzai S. A modular approach to quality of life assessment in cancer clinical trials. Recent results. Cancer Res 1988;111:231-49.

32 Aaronson NK, Bakker W, Stewart A, et al. A multi-dimensional approach to measurement of quality of life in lung cancer clinical trials. In: Paronson NK, Beckman J, eds. The quality of life of cancer patients. New York: Raven Press, 1987.

33 Cella DF, Orofiamma B, Holland JC, et al. The relationship of psychological distress, extent of disease and performance status in patients with lung cancer. Cancer 1987;60:1661-7.

34 Hughes JE. Depressive illness and lung cancer. II. Followup of inoperable patients. Eur J Surg Oncol 1985;11:21-4.

35 Bakker W, Nijhuis-Heddes JMA, Van Oosterom AT, Noordijk EM, Hermens J, Dijkman JH. Combined modality treatment of short duration in small cell lung cancer. Eur $J$ Cancer Clin Oncol 1984;20:1033-7.

36 Allan SG, Gregor A, Cornbleet MA, et al. Phase II trial of vindesine and VP16-213 in the palliation of poor prognosis and elderly patients with small cell lung cancer. Cancer Chemother Pharmacol 1984;13:106-8.

37 Coates A, Dillenbeck CF, McNeil DR, et al. On the receiving end-II. Linear analogue self assessment (LASA) in evaluation of aspects of the quality of life of cancer patients receiving therapy. Eur J Cancer Clin Oncol 1983;19:1633-7.

38 Geddes DM, Dones L, Hill E, et al. Quality of life during chemotherapy for small cell lung cancer: assessment and use of a daily card in a randomised trial. Eur J Cancer 1990;26:484-92.

39 Splinter TAW. Chemotherapy in advanced non-small cell lung cancer. Eur J Cancer 1990;26:1093-9.

40 Harvey VJ, Slevin ML, Cheek SP, et al. A randomised trial comparing vindesine and cisplatinum to vindesine and methotrexate in advanced non small cell lung carcinoma. Eur J Cancer Clin Oncol 1987;23:1615-9.

41 Bakker W, Van Oosterom AT, Aaronson NK, Van Bremkelen FJM, Bins MC, Hermans J. Vindesine, cisplatin and bleomycin combination chemotherapy in non-small cell lung cancer: survival and quality of life. Eur J Cancer Clin Oncol 1986;22:963-70.

42 Minet P, Bartsch P, Chevalier P, et al. Quality of life of inoperable non-small cell lung carcinoma. A randomised phase II clinical study comparing radiotherapy alone and combined radio-chemotherapy. Radiother Oncol 1987; 8:217-30.

43 Kaasa S, Mastekaasa A, Naess S. Quality of life of lung cancer patients in a randomised clinical trial evaluated by a psychosocial well-being questionnaire. Acta Oncol 1988;27:335-42.

44 Kaasa S, Mastekaasa A. Psychosocial well-being of patients with inoperable non-small cell lung cancer. Acta Oncol 1988;27:829-35.

45 Nou E, Aberg T. Quality of survival in patients with surgically treated bronchial carcinoma. Thorax 1980 35:255-63.

46 Nou E, Eklund G. Bronchial carcinoma IV: A methodological evaluation of the vitagram index for measurement of quality of survival. Scand J Respir Dis 1979;104 (suppl):131-72.

47 Greenberg ER, Chute CG, Stukel T, et al. Social and economic factors in the choice of lung cancer treatment. $N$ Engl J Med 1988;318:612-7.

48 Jennett $B$, Buxton $M$. When is treatment for cancer economically justified? Discussion paper. J Soc Med 1990, 83:25-8. 